strychnia, iron, and quinine; but had uninterruptedly grown worse. Finding, on inquiry, that seven years previously he had suffered from a chancre for which he took mercury till his teeth were loose, and which was followed by sore-throat but by no skin eruption, $I$ at once gave him iodide of potassium. In a month be could walk a mile with the help of two sticks, and could hold his urine for a short time. In another fortnight he could walk a little way without sticks, and a month after this he could manage four miles by the help of a stick. His reproductive powers had returned, and be had much more command over his bladder and sphincter ani. Six months after his first visit to the hospital be had almost entirely recovered his usual health, could walk six miles "at a spell," and more than that in the day. His grasp was equal and perfect with either hand. There was still a little hesitation in speech, but he had ceased to employ the wrong word. There was also some slight remaining weakness of the sphincter ani. He told me he could feel nothing the matter with him, and was about to start for one of the colonies. I advised him to resort to the iodide (of which he had taken thirty grains daily for six months) in case he felt any tendency to a return of his ailment.

This man must have had a double lesion-one situated in the district of the left middle cerebral artery, and the other in the sheath of the spinal cord, most likely in the lower dorsal portion. Leaving the previous history of the patient and the results of treatment out of the question, this pathological condition alone pointed to interrupted communication in various parts of the sensory and motor tracts. Now, as regards the intracranial lesion, the resulting symptoms were consistent with softening consequent upon $\in$ mbolism of the middle cerebral artery, or with cerebral hæmorrhage in the region supplied by this vessel, or with pressure from some growth. But the lesion of the cord, if it were not dependent upon a partial myelitis, must be caused by some form of tumour, cancerous or otherwise, and the improbability of the almost coincident appearance, in a man of this age, of tumours which were not syphilitic in two parts of the cerebro-spinal axis, would practically decide the question. On the other hand, there would be nothing at all inconsistent in the occurrence of gummatous tumours about the same time in various portions of the cerebro-spinal membranes. The history, however, and the excellent recovery from an exceedingly grave state under iodide, left the nature of the disease in no manner of doubt.

I hope to be permitted, in another paper, to illustrate some other phases of nervous disorder consequent upon syphilis.

\section{A CASE OF}

\section{REMOVAL OF THE WHOLE OF THE LOWER LIP FOR EPITHELIOMA, WITH RESTORA- TION BY CHEILOPLASTIC OPERATION.}

\section{By JOHN EWENS, L.R.C.P. \& L.R.C.S. EDIN.}

REPORTS of cheiloplastic operations are sufficiently rare to induce me to think that an account of the following case may prove interesting. In THE LANCET of August 1st, 1868, will be found the details of a similar case, on which I operated about six months previously. At the expiration of nearly five years the case still remains a most successful one. The man, aged eighty years, is in the enjoyment of excellent health, and his artificial lip is all that can be desired for articulation, retaining saliva, protecting the teeth, \&c. In the case I now relate the disease had advanced to a much greater extent in much less time, aggravated, I have no doubt, by the irritating applications of a female, under whose care be had placed himself for more than a year.

Conservative and restorative surgery justly claims a peculiar interest in the practice of every intelligent surgeon; and $I$ know nothing more gratifying than to be enabled, by the excision of a diseased joint or the removal of necrosed bone, to save for a portion of its functions a limb which otberwise must remain practically useless, if not dangerous to life; or by the restoration of any portion of the face, removed on account of incurable disease, to render it useful, comparatively ornamental, and at least preferable to an ugly chasm, more particularly when applied to operations on the lower lip, the integrity of which is essential for so many obvious purposes. Having this object in view, and being encouraged by the complete success of my former case, I determined to give this patient the benefit of the operation, although, from the greater extent of the structures involved by the disease, more difficulties presented them selves.

Mr. B. A-, aged sixty-five years, looks much older, has always enjoyed good general bealth, but has a sallow look ; moderate smoker; has an extensive epithelioma, involving the whole of the lower lip, a considerable portion of which is destroyed by ulceration. The disease has existed upwards of two years, commencing a little on the left side of the mesial line, and gradually extending until it involved the whole of the lower lip, and at the present time not only its free portion, but the subjacent structures close to the boue are affected with the disease almost to the chin. The appearances aptly correspond with Mr. Wood's description of "cancerous phagedena" in his admirable lecture on Epithelioma in a late number of THE LANCET.

The nature of the operation for removal of the diseased parts and that for restoring the lip baving been fully explained to the patient, with the risks attending it, and the possibility of the disease returning, he willingly assented; and on July 25th, 1872 (assisted by my friend Dr. Fielding, of Milton Abbas), under the influence of chloroform, I operated in the following manner:-The arteries being well controlled on both sides by the pressure of the finger and thumb of assistants, and the diseased part firmly seized by my left finger and thumb, a free incision was made through the mucous membrane at the angle of junction between the lip and gum, and carried downwards as far as necessary to isolate the tumour $(\mathrm{T}, \mathrm{T})$, which was then removed by an in cision from one angle of the mouth to the other, in the course of the line A, C, B. Incisions were then made in the course of the dotted line $C, D, F$, and $C, E, G$, the shaded parts re-

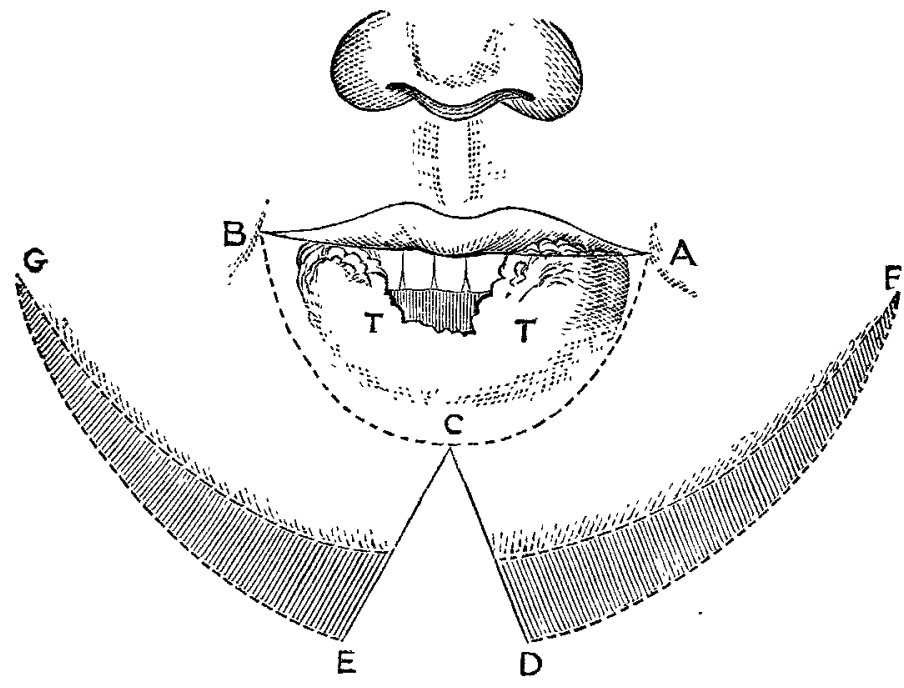

presenting the skin beneath the chin. The flaps were dissected up and united (the upper borders parallel with the line $A, B$ ) in the median line by three hare-lip pins, the lower one also transfixing the apex of the triangle (C, E, D), which was slightly liberated from the subjacent structures, and thus received between the flaps, forming a means of attachment and support for them. The bleeding soon ceased, and only one vessel required ligature, torsion being sufficient for the rest. The parts were dressed with carbolic oil, the chin well supported with a bandage passing over the head, and strips of lint were placed between the new lip and lower jaw, also in the triangular spaces left by the flaps being dissected up, for the purpose of preventing too early cicatrisation. Rapid healing took place, and the general health improved, the patient being well supported with eggs, milk, and brandy, and the parts carefully syringed after each administration of food.

The only thing worthy of note in the after-treatment was the necessity of slitting up a sinus which formed in the course of the upper pin, which was not taken out until the fourth day; also the growth of some unhealthy soft 
granulations near the corners of the mouth, evidently caused by tartar on the teeth. These speedily subsided on removal of the exciting canse, with applications of nitrate of silver and interposition of dry lint.

The patient living fire miles distant from $m y$ residence, I was obliged, after the first week, to entrust the occasional dressing of the wound to his son, and rather more adhesion between the new lip and gum occurred than $\mathrm{I}$ had intended, but a fair amount of movement of the new lip is obtained, and with an effort the mouth can be completely closed. The moustache and beard are now (October 31st) grown, and he has lost the sallow complexion before mentioned. The parts are perfectly firm and healthy, and not the least pain or inconvenience is felt. No dribbling of saliva has occurred from the commencement.

I would earnestly urge the importance of early removal, by the knife, of suspicious growths about the lips, and the fallacy of trifling with them by such injurious applications as caustics; several of the cases which have come under my notice having been thus aggravated, and a more extensive operation thereby rendered necessary. Besides, admitting that powerful caustics may occasionally eradicate the disease, I submit it as a question for consideration whether the pain, to say nothing of the annoyance and trouble of repeated applications, is not, on the whole, much greater than that caused by one rapid and comparatively simple operation by the knife, especially under the beneficent influence of chloroform.

The freedom from pain in the after-treatment of the case was very marked, and can, I think, only be attributed to the specific action of the carbolic oil on the sore parts, the patient never once complaining of the dressing of the wound. This I have noticed in other operations involving a larger extent of granulating surface.

I think it highly important also, and shall see to it in any future case, that the teeth should be carefully cleansed from tartar before or at the time of operation, as there cannot be a doubt that the healing of the wound was retarded two or three weeks from this cause, and at one time gave me some cause for anxiety.

Before concluding, I would advert for a moment to the very excellent results obtained in some cases in my own practice, and that of other surgeons, in which the whole of one side of the lower lip has been involved in the disease, where the operation has consisted in removing the part by a $\mathbf{V}$-shaped incision, making another incision from the angle of the mouth about three-fourths of an inch into the cheek, and uniting the mucous membrane and the skin of the lower part with sutures, thereby greatly diminishing the strain upon the bealthy balf of the lip. By this process no more deformity results than after the remoral of a smaller section for a less amount of disease.

February, 1873.-The patient still continues well, and without any indications of recurrence of disease; and some persons who have accidentally met him have not noticed that any operation has been performed.

Cerne Abbas.

\section{NOTES ON OBSTETRIC CASES.}

By THOMAS SATAGE, M.D., F.R.C.S.,

SURGEON TO THE HOSPITAL FOR WOMHN AND TO THE BIRMINGHAM LYING-IN CHARITY.

THE following is, a short and rather rough record of 1400 midwifery cases which have been attended by me in continuous succession, at or nearly at the full term. Of these, 1437 children were born-viz., 778 males and 659 females. Ramsbotham gives the proportion of males to females as 51.736 to 48.264 per cent. Thirty-five cases were twins and 1 triplets. Of the 1400 women, 285 were primiparæ, or about 1 in every 5. Nine maternal deaths occurred. Of the children, 1398 were born alive and 39 still-born, or about 97 per cent. alive and $2 \%$ per cent. still. Ramsbotham gives children born living as 96.3 per cent., and still-born 3.7 per cent. No notes have been taken of the diseases of the puerperal state, though there was the usual complement of sucb, as milk fever, mammary abscesses, metritis, ovaritis, parametritis (which occurred in one instance), peri- tonitis, and the generic disease known as puerperal fever. The diseases of pregnancy were not noted. The effect of sex in children upon their being born alive or still is seen by the fact that there were 39 still-born, of which 21 were males and 18 females. A return has been published showing that they are as 140 males to 100 females. Sir James Simpson says that of the chiidren that die in utero, and before the commencement of labour, as large a proportion are females as males; and he gives as his sixth proposition, in his remarks on Fotal Dystocia, that of those children who are born alive more males than females are seen to suffer from the morbid states and injuries resulting from parturition.

The average duration of labour may be taken to be agreed upon by all to be longer with males than females. In this series this was not observed, except what appears from the instrumental deliveries, where there were 129 male to 91 female children. The duration of labour is also influenced by the position of the presentation in vertex cases; as, where it was occipito-posterior, of which there were 19 instances, the forceps were used 12 times ( 6 males and 6 females), and of the 6 born by natural efforts 1 was male and 5 female. These instrumental deliveries may be taken as a guide as to duration; for, whatever may be the views of any particular practitioner as to using artificial aid, sooner or later, in the second stage, it would always be the case that forceps would be applied in those that were the more tedious, even though in the one case they were used early, or, in the other, deferred until exhaustion had set in.

Interspersed among these 1400 cases, but not included with them, were 53 premature deliveries, with 41 male and 14 female footuses, 2 being twin cases. Those were called premature where the sex was easily distinguishable, but where the child was not viable-viz., at about or under the 224 th day.

There is little to say of the use of ergot. In the earlier cases I used it pretty frequently, and the forceps less; but of late $I$ have almost entirely discarded it as a means of accelerating delivery, having much more faith in the greater certainty and safety of the forceps. A case occurred recently which appeared to justify its condemnation. A woman, in labour with her eighth or ninth child, with dilated os and large roomy pelvis, was in a state of inertia; the child was distinctly felt by her immediately before her draught of two drachms of ext. ergot. liq. The uterus was almost at once set into contraction, and in about twenty minutes an asphyxiated dead child was born. Of course, these remarks do not apply to ergot as a therapeutic remedy or to its action on the uterine fibre, but merely to its administration before delivery where there is no fear or prospect of hæmorrhage, and where the application of the forceps would at once accomplish delivery.

Chloroform was rarely given in the cases that progressed satisfactorily, except at the urgent solicitation of the patient, although in many of the operative cases, where it was deemed advisable to lessen shock, it was pushed to the surgical degree. When given, it was given pure, and not mixed with either ether or alcohol. There seems to be a very general feeling in its favour in midwifery at the present time. I cannot speak personally very much of it, as I feel a little prejudiced against it, and so have not resorted to it as many practitioners do in the natural cases. I have been inclined to think that it disposes to flooding, and I know this opinion is shared by many.

The vertex presented 1366 times in the 1437 birtbs, being, as is well known, far more frequent than any other presentation. It would seem quite impossible to diagnose the exact position of the head, according to Naegele's division, in every case of labour attended, taking them successively, though in many cases it was easily made out, and it was constantly seen that the first position was by far the most frequent-viz., with the long diameter of the head in the right oblique pelvic diameter. In many of the occipitoposterior cases it was difficult to say what caused the delay, when the vertex was at the brim, where the pains were active, and where no great disproportion existed. Of these latter there were 19, 8 male and 11 female children, forceps being used in 12 and craniotomy in 1.

The breech presented 31 times, or about 1 in $47 \frac{2}{3}$ cases. Dr. Meadows gives their frequency as 1 in $52 \frac{1}{3}$ cases. Of these 31,24 children (10 males and 14 females) were born alive; and 7 ( 3 males and 4 females) were still-born. The 